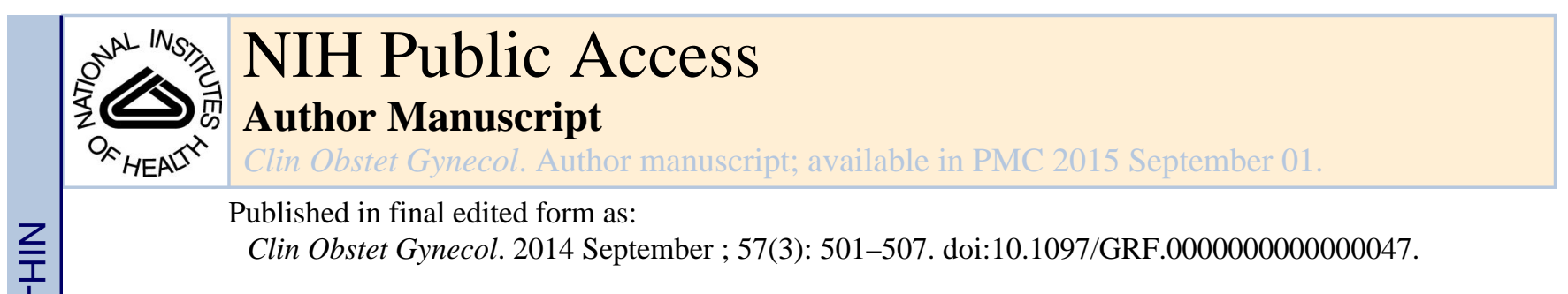

\title{
OBESITY AND CONTRACEPTION
}

\author{
Sheila K Mody, M.D., M.P.H. and Michelle Han, M.D \\ University of California San Diego, Department of Reproductive Medicine, 200 West Arbor Drive, \\ San Diego, California 92103
}

\section{Introduction}

Approximately $51 \%$ in the United States each year are unintended. ${ }^{1,2}$ It is likely that many of these unintended pregnancies are among obese women, since obesity is significantly associated with contraceptive nonuse. ${ }^{3}$ In fact, women with a Body Mass Index (BMI) greater than $35 \mathrm{~kg} / \mathrm{m}^{2}$ are less likely to use contraceptives than women with a BMI less than $25 \mathrm{~kg} / \mathrm{m}^{2} .4$

Unintended pregnancy in obese women is especially worrisome because of the higher pregnancy risks associated with obesity. ${ }^{5}$ Maternal risks include a higher rate of cesarean section, gestational hypertension, gestational diabetes, and preeclampsia. ${ }^{5-7}$ Fetal risks include macrosomia, stillbirth, neural tube defects, orofacial defects, cardiac anomalies, and hydrocephalus. ${ }^{8-9}$ Additionally, infants born to obese mothers also have long-term sequelae of childhood obesity and type 2 diabetes. ${ }^{10-11}$

It is important for clinicians to address family planning needs of obese patients in order to prevent unintended pregnancy and subsequent obstetrical complications. Obese women of reproductive age in particular would benefit from contraceptive counseling since they may underestimate their fertility due to irregular menses secondary to anovulation. In addition, obese women may desire to use contraceptives so they can optimize their weight prior to conceiving so they can have healthier pregnancies.

\section{Risks of Weight Gain with Hormonal Contraceptives}

Obese women may avoid contraceptives because of fear that hormones may contribute further to weight gain. However, most studies have indicated that weight gain with many contraceptive methods is similar to age-related weight gain. ${ }^{12}$ A Cochrane review indicated no relationship between combination oral contraceptives or the patch on weight gain. ${ }^{12}$ The relationship between weight gain and progestin-only methods is also not well established. A Cochrane review found limited evidence of weight gain in five out of sixteen studies, with small changes in weight or body fat percentages with Depot-Medoxyprogesterone (DMPA), Norplant, and the levonorgestrel intrauterine device (LNG-IUD). ${ }^{13}$ Most studies found a weight gain of less than 2 kilograms ( $\mathrm{kg}$ ) up to 12 months for these methods, and a possible increase in body fat and decrease in lean body mass compared to users of non-hormonal

University of California San Diego, Department of Reproductive Medicine, 200 West Arbor Drive, San Diego, California 92103, (619) 543-6777 (phone), (619) 543-3703 (fax), smody@ucsd.edu. 
contraceptives. ${ }^{13}$ While the study on the LNG-IUD in the review reported a statistically significant small change in body fat percentage, this increase could be attributed to aging. ${ }^{13}$

The one contraceptive method that has been most associated with minimal weight gain in multiple studies is DPMA, with a typical gain of about 5 pounds in the first year. ${ }^{13}$ Mean weight differences between DPMA and the non-hormonal IUD in one study was $2.28 \mathrm{~kg}$ at year $1,2.71 \mathrm{~kg}$ at year 2 , and $3.17 \mathrm{~kg}$ at year $3 .{ }^{14} \mathrm{~A}$ study on DPMA use postpartum found a weight gain of about 3-6 pounds over one year of use. Patients who were overweight or obese prior to pregnancy had a higher risk for weight gain during this time period. ${ }^{15}$ Those with a BMI of $26-35 \mathrm{~kg} / \mathrm{m}^{2}$ had a 8.8 pounds weight gain from baseline (6 weeks postpartum) to 1 year versus non-overweight women actually lost weight. While DMPA is a good contraceptive method for some patients, other contraceptive options should be considered for women trying to lose weight.

\section{Contraceptive Methods Efficacy in Obese Women}

Most of the original studies on contraceptive efficacy excluded obese women from the trials. Several studies have recently demonstrated efficacy of certain contraceptive methods among overweight women. Contraceptive methods such as the intrauterine device theoretically should not be affected by BMI, as the mechanism is largely local. ${ }^{16} \mathrm{An}$ analysis of the contraceptive CHOICE Project found that the 3 year failure rates of intrauterine devices (both copper and LNG) in overweight and obese women were less than 1 per 100 womenyears and had no variation by BMI. ${ }^{16}$ Thus both these methods were considered safe and efficacious in obese women. However, insertion of an IUD maybe more difficult in obese women due to visualization and body habitus, but the use of ultrasound may be helpful. ${ }^{17}$

Food and Drug Administration (FDA) labeling for packaging of the etonogestrel implant states that women who weigh greater than $130 \%$ of ideal body weight were not studied in clinical trials, and that overweight women may have lower serum concentrations of etonogestrel. ${ }^{18}$ This could theoretically mean that the subdermal implant may be less effective in overweight women. Although evidence suggests that the serum etonogestrel concentrations in obese women with the subdermal implant are lower than in normal-weight women, analysis from the CHOICE Project suggests this does not amount to higher failure rates since levels are maintained above the minimal amount needed to prevent ovulation. ${ }^{16,19}$

There are only a few studies on the efficacy studies of the patch in obese women. One study demonstrated that women weighing greater than $90 \mathrm{~kg}$ had a significantly increased failure rate than women weighing less than $90 \mathrm{~kg} .{ }^{20}$ However, an analysis from the CHOICE Project showed no increase in failure rate by BMI in users of the patch. ${ }^{21}$

The progestin-only contraceptive pill remains an efficacious method among obese women. A recent study of greater than 50,000 women found no association between the efficacy of the progestin-only pill and obesity. ${ }^{22}$ Moreover, the progestin-only pill has been shown to not increase the risk of thrombosis or cardiovascular disease, which may make it a safe alternative method for obese women who have increased risk of thromboembolism and therefore cannot take combined oral contraceptives. ${ }^{23}$ 
The vaginal contraceptive ring, which contains $15 \mathrm{mcg}$ EE and $120 \mathrm{mcg}$ etonogestrel, is also a reasonable option for obese women. ${ }^{24}$ Women who use the vaginal ring compared to oral contraceptives or the patch are exposed to lower amounts of estrogen, with more stable and precise serum levels. ${ }^{24}$ It has been hypothesized that the ring may offer higher hormone levels for obese women than oral contraceptives because the hormones are absorbed directly into the vaginal mucosa and do not go through the first-pass liver metabolism. ${ }^{25}$

Studies are conflicting regarding the efficacy of oral contraceptives in obese women. A Cochrane review suggests overweight women $\left(\mathrm{BMI}>25 \mathrm{~kg} / \mathrm{m}^{2}\right.$ ) are significantly more likely to get pregnant on oral contraceptives. ${ }^{26}$ However some studies have shown there is no overall difference in failure rates according to BMI and body weight. ${ }^{21,27}$ Although data is conflicting, overall conclusions suggest unintended pregnancy rates among overweight women using oral contraceptives are similar or slightly higher than that among nonoverweight women. ${ }^{27}$

Pharmacokinetic (PK) parameters (drug clearance, half-life, AUC, time to reach steady state) of oral contraceptive metabolism were studied in obese women, with no clear conclusions. Overall, all the PK studies have shown different PK parameters for obese women compared to normal-weight women, but it is unknown whether these changes are significant for decreased efficacy of oral contraceptives. ${ }^{28}$ Several PK studies have suggested increased follicular development for obese women on oral contraceptives (indicating contraceptive failure), while some have shown no significant differences in follicular size. ${ }^{28} \mathrm{~A}$ study by Edelman correlated PK parameters with end-organ activity (ovarian follicle development by ultrasound, cervical mucus assessment). ${ }^{29}$ Although obese women had significant changes in their PK parameters, the severity of these changes did not correlate with ovulation, since many of the women had evidence of poor end-organ suppression without overt evidence of ovulation.

At study by Westhoff investigated the pharmacokinetics of oral contraceptives' s containing $30 \mathrm{mcg}$ of ethinyl estradiol (EE) and $150 \mathrm{mcg}$ of levonorgestrel (LNG).$^{30}$ Obese women were found to have a lower area under curve, maximum concentration (Cmax), and time needed to reach Cmax, and a statistically significant increased half-life for EE. Therefore it was theorized OCPs may take longer periods of time to reach a steady state in obese women, jeopardizing the 7 day placebo and initiation periods in the typical oral contraceptive cycle. However, twice weekly vaginal ultrasounds were performed for the participants in the study and no difference in ovarian follicular activity by BMI was found. Therefore, the efficacy was maintained in obese women since their minimum concentrations of hormones did not drop below the level needed to prevent ovulation.

\section{Bariatric Surgery}

Approximately half of bariatric surgeries are done among women of reproductive age. ${ }^{31}$ The general recommendation for women who undergo bariatric surgery is to wait 1-2 years after surgery before attempting to conceive. ${ }^{32}$ The American Congress of Obstetricians and Gynecologists (ACOG) recommends postponing pregnancy for at least 12-18 months. ${ }^{33}$ This recommendation is based on the theoretical risk of malnourishment to the fetus during 
the rapid weight loss following bariatric surgery. Although this waiting period is the ACOG recommendation, there may be unintended pregnancies during this waiting time due to lack of proper contraceptive use.

Many of the women pursuing bariatric surgery are anovulatory due to their obesity become ovulatory post-surgery since a small amount of weight loss can restore ovulatory function in obese women. ${ }^{34}$ Therefore there may be an increase in fertility from these procedures. Changes in body image coupled with increased fertility after surgery may account for a possible increase in unintended pregnancies. ${ }^{34}$ Among adolescents who underwent bariatric surgery, the rate of unintended pregnancy was high. One study documented a $12.8 \%$ pregnancy rate among adolescent females who underwent gastric bypass surgery, which was more than double the rate among their peers. ${ }^{35}$ Contraceptive counseling is therefore especially important for these women.

Often women are not aware that their contraceptive options may be limited by the type of bariatric surgery they underwent. One study revealed that only $21 \%$ of women from an urban hospital who were post-bariatric surgery were referred to a gynecologist for contraceptive counseling, and $16 \%$ did not use any contraceptive for a year. ${ }^{36}$ Use of long acting reversible contraception (LARC) was infrequent, as only $4 \%$ of the women used IUDs.

There are only few studies on the effectiveness of hormonal contraceptives in post-bariatric surgery patients. Based on the existing published literature, the United States Medical Eligibility Criteria for Contraceptive Use (USMEC) does not recommend the use of oral contraceptives among women who have undergone malabsorptive bariatric surgery procedures such as the Rouex-Y gastric bypass (Table 1). ${ }^{37,38}$ Malabsorptive procedures include the jejunoileal bypass, bilio-pancreatic diversion with or without duodenal switch, and the Roux-en-Y bypass. With these procedures there is concern for decreased absorption of the oral contraceptive with possible impact on efficacy.

The existing studies have suggested that levels of circulating hormones may be lower in post-malabsorptive bariatric surgeries most likely due to decreased intestinal absorption but this effect on actual contraceptive failure is unclear. ${ }^{37}$ One small study showed higher oral contraceptive failure rate for patients post-biliopancreatic diversion. ${ }^{39}$ Overall, studies suggest oral contraceptives alone may not be sufficiently reliable for post-malabsorptive surgery patients but more research is needed. Currently, there is a study funded by the Society of Family Planning further exploring this topic. ${ }^{40}$

With regards to non-oral contraception, there are even fewer studies on efficacy in this population. One small study has suggested that the etonogestrel releasing subdermal implant following malabsorptive procedures remains an effective method since serum levels remain above the minimal concentration needed for contraceptive effectiveness. ${ }^{41}$ The LNG-IUD is also an acceptable option by adolescents undergoing bariatric surgery. ${ }^{34}$ For restrictive bariatric surgery such as lap band and gastric sleeves, all contraceptive methods are acceptable according to the USMEC. ${ }^{38}$ 
There are recent medical pharmacotherapies for weight loss. A need for effective contraception needs to be addressed by health care professionals who take care of obese patients on certain teratogenic weight loss drugs. The most effective currently available antiobesity drug phentermine/topiramate combination therapy has the severe teratogenic risk of cleft lip with or without cleft palate. ${ }^{42}$ Women are required to have a negative pregnancy test prior to taking the drug, but should also use highly effective contraceptives. ${ }^{42}$

\section{New Research and Next Steps}

There are several recent research findings with regards to obesity and contraception, but much more needs to be done. More studies are needed on the efficacy of oral contraceptives in obese women, as multiple small trials and limited PK studies show conflicting data. $^{21,26-30}$

One finding that may have a larger societal impact is the publication from Glasier indicating that ulipristal acetate is a more effective emergency contraceptive compared to LNG among women with a BMI $>25 \mathrm{~kg} / \mathrm{m}^{2} .{ }^{43}$ Obese women taking LNG as emergency contraceptive were 4 times as likely to get pregnant than non-obese women taking LNG. Comparatively obese women taking ulipristal acetate had no statistically significant difference in pregnancy rates compared to non-obese women. ${ }^{43}$ LNG has a decrease in efficacy with increasing BMI, approaching a point where it is no different from pregnancy rates among women not using any form of emergency contraceptive at a BMI of $26 \mathrm{~kg} / \mathrm{m}^{2}$. Ulipristal acetate does not show this null point of efficacy until a BMI of $35 \mathrm{~kg} / \mathrm{m}^{2}$ is reached. ${ }^{43}$

\section{Recommendations}

With nearly one third of the United States population meeting the criteria for being overweight, there is still a tremendous need for more research on contraceptive efficacy among this population. Contraceptive trials should include more obese patients. ${ }^{44}$ The National Institute of Health has recognized this need and has held a working group around this issue. As clinicians caring for this growing population, it is important that we continue to stay informed of the emerging literature regarding this important topic. Our key recommendations for the clinician managing the obesity and contraception are:

1. Educate obese patients about the obstetrical risk associated with obesity and discuss contraceptive options during weight optimization.

2. Review with all patients that the weight gain with contraception is typically the same as age related weight gain with a few exceptions.

3. Explain to obese patients that there is limited literature on the efficacy of contraceptive methods among obese women. Emphasize that even if there may be slightly less efficacy, it is still better to use a contraceptive than no contraceptive to prevent unintended pregnancy.

4. For patients who have undergone bariatric surgery, base your contraceptive method recommendations on the USMEC guidance. Specifically, avoid oral contraceptives among women who have malabsorptive procedures. 
5. For women with BMI $>35 \mathrm{~kg} / \mathrm{m}^{2}$, consider using ulipristal acetate as first line oral emergency contraceptive.

\section{References}

1. Guttmacher Institute fact sheet on unintended pregnancy in the United States. 2013 Available from: http://www.guttmacher.org/pubs/FB-Unintended-Pregnancy-US.html.

2. Mosher WD, Jones J, Abma JC. Intended and unintended births in the United States, 1982-2010. Natl Health Stat Report. 2012 Jul 24.(55):1-28.

3. Chuang CH, Chase GA, Bensyl DM, Weisman CS. Contraceptive use by diabetic and obese women. Women's Health Issues. 2005; 15(4):167-173. [PubMed: 16051107]

4. Vahratian A, Barber JS, Lawrence JM, Kim C. Family planning practices among women with diabetes and overweight and obese women in the 2002 National Survey For Family Growth. Diabetes care. 2009; 32(6):1026-1031. [PubMed: 19279299]

5. Heslehurst N, Simpson H, Ells LJ, Rankin J, Wilkinson J, Lang R, Brown TJ, Summerbell CD. The impact of maternal BMI status on pregnancy outcomes with immediate short-term obstetric resource implications: a meta-analysis. Obes Rev. 2008; 9:635-683. [PubMed: 18673307]

6. O'Brien TE, Ray JG, Chan WS. Maternal body mass index and the risk of preeclampsia: a systematic overview. Epidemiology. 2003; 14:368-374. [PubMed: 12859040]

7. Chu SY, Callaghan WM, Kim SY, Schmidt CH, Lau J, England LJ, Dietz PM. Maternal obesity and risk of gestational diabetes mellitus. Diabetes Care. 2007; 30:2070-2076. [PubMed: 17416786]

8. Mills JL, Troendle J, Conley MR, Carter T, Druschel CM. Maternal obesity and congenital heart defects: a population- based study. Am J Clin Nutr. 2010 Jun; 91(6):1543-1549. [PubMed: 20375192]

9. Shaw GM, Carmichael SL. Prepregnant Obesity and Risks of Selected Birth Defects in Offspring. Epidemiology. 2008; 19(4):616-620. [PubMed: 18552593]

10. Olson CM, Strawderman MS, Dennison BA. Maternal Weight Gain During Pregnancy and Child Weight at Age 3 Years. Maternal \& Child Health Journal. 2009; 13:839-846. [PubMed: 18818995]

11. Shankar K, Harrell A, Liu X, Gilchrist JM, Ronis MJ, Badger TM. Maternal obesity at conception programs obesity in the offspring. American Journal of Physiology - Regulatory, Integrative, and Comparative Physiology. 2008; 294:R528-R538.

12. Gallo MF, Lopez LM, Grimes DA, Carayon F, Schulz KF, Helmerhost FM. Combination contraceptives: effects on weight. Cochrane Database of Systematic Reviews. 1:CD003987CD003987.

13. Lopez LM, Edelman A, Chen M, Otterness C, Trussell J, Helmerhost FM. Progestin-only contraceptives: effects on weight. Cochrane Database of Systematic Reviews. 7:CD008815CD008815.

14. Pantoja M, Medeiros T, Baccarin MC, Morais SS, Bahamondes L, Fernandes AM. Variations in body mass index of users of depot-medroxyprogesterone acetate as a contraceptive. Contraception. 2010; 81(2):107-111. [PubMed: 20103446]

15. Nyirati CM, Habash DL, Shaffer LE. Weight and body fat changes in postpartum depotmedroxyprogesterone acetate users. Contraception. 2013; 88(1):169-176. [PubMed: 23177262]

16. Xu H, Wade JA, Peipert JF, Zhao Q, Maden T, Secura GM. Contraceptive failure rates of etonogestrel subdermal implants in overweight and obese women. Obstetrics and gynecology. 2012; 120(1):21-26. (2012). [PubMed: 22678035]

17. Weisberg E. Contraceptive options for women in selected circumstances. Best Practice \& Research Clinical Obstetrics and Gynaecology. 2010; 24:593-604. [PubMed: 20434405]

18. NEXPLANON® (etonogestrel Implant) HCP - Official Website for Health Care Providers. MERCK, n.d. Web. 2014 Feb 23.

19. Mornar S, Chan LN, Mistretta S, Neustadt A, Martins S, Gilliam M. Pharmacokinetics of the etonogestrel contraceptive implant in obese women. Am. J. Obstet. Gynecol. 2012; 207(2):110.e1110.e6. [PubMed: 22717269] 
20. Zieman M, Guillebaud J, Weisberg E, Shangold GA, Fisher AC, Creasy GW. Contraceptive efficacy and cycle control with the Ortho Evra/Evra transdermal system: the analysis of pooled data. Fertil Steril. 2002; 77:S13-S18. [PubMed: 11849631]

21. McNicholas C, Zhao Q, Secura G, Allsworth JE, Madden T, Peipert JF. Contraceptive failures in overweight and obese combined hormonal contraceptive users. Obstet. Gynecol. 2013; 121:585592. [PubMed: 23635622]

22. Dinger JC, Cronin M, Mohner S, Schellschmidt I, Minh TD, Westhoff C. Oral contraceptive effectiveness according to body mass index, weight, age, other factors. American Journal of Obstetrics and Gynecology. 2009; 201(263):e1-e9. [PubMed: 19481720]

23. Mansour D. Implications of the growing obesity epidemic on contraception and reproductive health. Journal of Family Planning and Reproductive Health Care. 2004; 30(4):209-211. (2004). [PubMed: 15530216]

24. Van den Heuvel MW, van Bragt AJ, Alnabawy AK, Kaptein MC. Comparison of ethinylestradiol pharmacokinetics in three hormonal contraceptive formulations: The vaginal ring, the transdermal patch and an oral contraceptive. Contraception. 2005; 72(3):168-174. [PubMed: 16102549]

25. Murthy AS. Obesity and contraception: Emerging issues. Seminars in Reproductive Medicine. 2010; 28(2):156-163. [PubMed: 20352564]

26. Lopez LM, Grimes DA, Chen M, Otterness C, Westhoff C, Edelman A, Helmerhorst FM. Hormonal contraceptives for contraception in overweight or obese women. Cochrane Database of Systematic Reviews. 2013; 4:CD008452-CD008452. [PubMed: 23633356]

27. Robinson JA, Burke AE. Obesity and hormonal contraceptive efficacy. Women's health. 2013; 9(5):453-466.

28. Edelman AB, Cherala G, Stanczyk FZ. Metabolism and pharmacokinetics of contraceptive steroids in obese women: a review. Contraception. 2010; 82(4):314-323. [PubMed: 20851224]

29. Edelman AB, Cherala G, Munar MY, Dubois B, McInnis M, Stanczyk FZ, Jensen JT. Prolonged monitoring of ethinyl estradiol and levonorgestrel levels confirms an altered pharmacokinetic profile in obese oral contraceptives users. Contraception. 2013; 87(2):220-226. [PubMed: 23153898]

30. Westhoff CL, Torgal AH, Mayeda ER, Pike MC, Stanczyk FZ. Pharmacokinetics of a combined oral contraceptive in obese and normal-weight women. Contraception. 2010; 81:474-480. [PubMed: 20472113]

31. Maggard MA, Yermilov Z, Maglione M, Newberry S, Suttorp M, Hilton L, Santry HP, Morton JM, Livingston EH, Shekelle PG. Pregnancy and Fertility Following Bariatric Surgery: a systematic review. JAMA. 2008; 300(19):2286-2296. [PubMed: 19017915]

32. Inge TH, Krebs NF, Garcia VF, Skelton JA, Guice KS, Strauss RS, Albanese Ct, Brandt ML, Hammer CM, Kane TD, Klish WJ, Oldham KT, Rudolph CD, Helmrath MA, Donovan E, Daniels SR. Bariatric surgery for severely overweight adolescents: Concerns and recommendations. Pediatrics. 2004; 114:217-223. [PubMed: 15231931]

33. American College of Obstetricians and Gynecologists Committee Opinion No. 315, September 2005. Obesity in pregnancy. Obstet Gynecol. 2005; 106:671-675. [PubMed: 16135613]

34. Hillman JB, Miller RJ, Inge TH. Menstrual concerns and intrauterine contraception among adolescent bariatric surgery patients. J Women's Health. 2011; 20:533.

35. Roehrig HR, Xanthakos SA, Sweeney J, Zeller MH, Inge TH. Pregnancy after gastric bypass surgery in adolescents. Obes Surg. 2007; 17:873-877. [PubMed: 17894144]

36. Mody SK, Hacker MR, Dodge LE. Contraceptive counseling for women who undergo bariatric surgery. Journal of Women's Health. 2011; 20(12):1785-1788.

37. Merhi ZO. Revisiting optimal hormonal contraception following bariatric surgery. Contraception. 2013; 87(2):131-133. [PubMed: 22840277]

38. CDC. U.S. medical eligibility criteria for contraceptive use, 2010. MMWR. 2010; 59(No.RR-4)

39. Gerrits EG, Ceulemans R, van Hee R, Hendrickx L, Totté E. Contraceptive treatment after biliopancreatic diversion needs consensus. Obes Surg. 2003; 13:378-382. [PubMed: 12841897]

40. Edelman A. Society of family planning clinical guidelines: contraceptive considerations in obese women. Contraception. 2009; 80 
41. Ciangura C, Corigliano N, Basdevant A, Moulty S, Decleves X, Touraine P, Lloret-Linares C. Etonorgestrel concentrations in morbidly obese women following Roux-en-Y gastric bypass surgery: three case reports. Contraception. 2011; 84:649-651. [PubMed: 22078197]

42. Gadde KM. Current pharmacotherapy for obesity: extrapolation of clinical trials data to practice. Expert opinion on pharmacotherapy. 2014 Feb 19. Epub ahead of print.

43. Glasier A, Cameron ST, Blithe D, Scherrer B, Mathe H, Levy D, Gainer E, Ulmann A. Can we identify women at risk of pregnancy despite using emergency contraception? Data from randomized trials of ulipristal acetate and levonorgestrel. Contraception. 2011; 84(4):363-367. [PubMed: 21920190]

44. Ogden CL, Carroll MD, Curtin LR, McDowell MA, Tabak CJ, Flegal KM. Prevalence of overweight and obesity in the United States, 1999-2004. JAMA. 2006; 295:1549-1555. [PubMed: 16595758] 
Table 1

United States Medical Eligibility Criteria for Contraceptive Methods for Bariatric Surgery 38

\begin{tabular}{|l|c|c|}
\hline \multirow{2}{*}{ Contraceptive Method } & \multicolumn{2}{|c|}{$\begin{array}{c}\text { Medical eligibility criteria for use in } \\
\text { patients bariatric surgery }\end{array}$} \\
\cline { 2 - 3 } & $\begin{array}{c}\text { Restrictive } \\
\text { Procedures }\end{array}$ & $\begin{array}{c}\text { Malabsorptive } \\
\text { Procedures }\end{array}$ \\
\hline Levonorgestrel intrauterine device & 1 & 1 \\
\hline Copper intrauterine device & 1 & 1 \\
\hline Progestin-only implant & 1 & 1 \\
\hline Progestin-only injectable & 1 & 1 \\
\hline Progestin oral contraceptive & 1 & $\begin{array}{c}\text { COCs: } 3 \\
\text { P/R: } 1\end{array}$ \\
\hline $\begin{array}{l}\text { Combined hormonal contraception- } \\
\text { combined oral contraceptives (COC), } \\
\text { transdermal patch(P), vaginal ring (R) }\end{array}$ & 1 & \\
\hline
\end{tabular}

Categories of medical eligibility criteria for contraceptive use

$1=$ A condition for which there is no restriction for the use of the contraceptive method

$2=$ A condition for which the advantages of using the method generally outweigh the theoretical or proven risks

$3=$ A condition for which the theoretical or proven risks usually outweigh the advantages of using the method

$4=$ A condition that represents an unacceptable health risk if the contraceptive method is used 